\title{
Assessment of Efficacy and Safety of Newly Formulated Natural Sun Protective Cream
}

\author{
S.T.V.Raghavamma ${ }^{1}$, M.V.Anjali ${ }^{2}$, N.Naga Amrutha ${ }^{2}$, T.Hemalatha ${ }^{2}$, \\ Rama Rao Nadendla ${ }^{3}$ \\ ${ }^{1-3}$ Department of Pharmaceutics, Chalapthi Institute of Pharmaceutical Sciences, Lam, Guntur, Andhra \\ Pradesh, India
}

Abstract: This research aims to formulate and evaluate the photo protective activity of an cream containing oil in water emulsion with different natural oils in varying proportions. The formulation is evaluated for its physical, chemical, microbiological and organoleptic properties for 28 days. The formulation was stable, white preparation with no recognisable irritancy when tested. SPF was determined to be 59.7 that can give both UV $A$ and $U V B$ protection. Aerobic microbial count was within the limit and there was no presence of Pseudomonas and yeast cells in the formulation. The newly formulated sunscreen cream was proved to exhibit a number of promising properties and attributes that might open new opportunities for the development of more efficient, safe, and cost-effective skin-care products.

Keywords: Ultraviolet light; sunprotection; sunscreen; SPF; UV Aand B protection.

\section{Introduction}

The skin is the body's first line of defense for external exposure. The signs of ageing skin are most visible in the skin. Although, ageing skin is not a threat of a person, it can have a detrimental effect on the psychology of a person ${ }^{[1]}$. Every year, about one million people are diagnosed with skin cancer and about 10.000 die from malignant melanoma ${ }^{[2]}$. Most skin cancer occurs on the areas of the body that are most frequently exposed to the sun, such as the face, neck, head and back of the hands ${ }^{[3]}$.

The harmful effects of solar radiation are caused predominantly by the ultraviolet (UV) region of the electromagnetic spectrum, which can be divided into UV A (400 to $320 \mathrm{~nm}$ ), UV B (320 to $290 \mathrm{~nm}$ ) and UV C $(290 \text { to } 200 \mathrm{~nm})^{[4]}$. UV C radiation is filtered out by the atmosphere before reaching earth. UV B radiation is not completely filtered out by the ozone layer and is responsible for the damage due to sunburn and pyrimidine dimers $^{[5]}$. UVA radiation reaches the deeper layers of the epidermis and dermis and provokes the premature ageing of the skin and is responsible for the generation of free radicals. UV B radiation is involved in $65 \%$ damage of all skin ${ }^{[6]}$. Exposure to ultraviolet radiation has pronounced acute and chronic effects on the skin. People are conscious of the possible dangers of photo ageing, sunburn and skin cancer, occurring as a result of sun overexposure ${ }^{[7]}$.

To prevent these harmful sun effects, body creams and lotions with added sunprotectants that scatters or reflects radiation were prepared ${ }^{[8]}$. Most of the sunscreens are applied topically on skin surface which leads to penetration of the ingredients into deeperlayers of skin which leads to toxic effects many of which are not desirable ${ }^{[9,10]}$. Hence this work aims at developing sunprotecting cream by using naturally available sunprotectants which will cause no irritation and also gives nourishment to the skin.

\section{Chemicals required}

\section{Materials And Methods}

The cream is formulated using olive oil, almond oil, carrot seed oil, avocado oil, beeswax, vitamin-E, lemon grass oil, glycerin and distilled water. All the chemicals are high gade purchased from Merk and HighMedia and compatable with skin.

\section{Preparation}

The cream was prepared by using the preocedure mentioned in the literature with slite modification ${ }^{[11,12,13]}$. Five different formulations were prepared and tested for SPF. The formulation with good stability was repoted in this paper. Cream base was prepared using measured quantity of oil components and adding them into aqueous components. The oil components contain emulsifier (cetostearyl alcohol and sodium lauryl sulphate in 9:1 proportions). The composition of oil and aqueous phase are mentioned in table1. Both aqueous and oil phases were heated in a water bath maintained at $80^{\circ} \mathrm{C}$ for aqueous phase and $70^{\circ} \mathrm{C}$ for oil phase and stired the components regularly to distribute the heat. Both the phases are mixed together by pouring the oil phase into the aqueous phase with vigorous stirring for 1-2 minutes to allow the formation of emulsion. The 
mixture was cooled to $55^{\circ} \mathrm{C}$ in a water bath with constant stirring until an emulsion is formed with required consistency.

Table 1: The ingredients of Oil phase and aqueous phase.

\begin{tabular}{|l|l|l|}
\hline S.No & Ingredients & Quantity/100g \\
\hline 1 & Emulsifying wax & $12 \mathrm{~g}$ \\
\hline 2 & Olive oil & $3 \mathrm{ml}$ \\
\hline 3 & Carrot seed oil & $2 \mathrm{ml}$ \\
\hline 4 & Avocado oil & $3 \mathrm{ml}$ \\
\hline 5 & Almond oil & $2 \mathrm{ml}$ \\
\hline 6 & Bees wax & $3 \mathrm{~g}$ \\
\hline 7 & Vitamin - E & $0.1 \mathrm{ml}$ \\
\hline 8 & Lemongrass oil & $0.1 \mathrm{ml}$ \\
\hline 9 & Glycerin & $9 \mathrm{ml}$ \\
\hline 10 & Distilled water & $35 \mathrm{ml}$ \\
\hline
\end{tabular}

\section{Spectrophotometric Analysis}

\section{Evaluation Studies}

Newly formulated sunprotective cream was analysed using using Hitachi U-3900H UV/Visible spectrophotometer, equipped with $1 \mathrm{~cm}$ quartz cell and a computer ${ }^{[14]}$. Aliquate $(1.0 \mathrm{~g})$ of the sample prepared was transferred to a $100 \mathrm{ml}$ volumetric flask, diluted with ethanol (Merck product, analytical grade), followed by spectrophotometric screening between 290 to $320 \mathrm{~nm}$. Absortion maxima was determined. Three determinations were made at each point using ethanol as a blank ${ }^{[15]}$. SPF values were determined using Mansur equation (equation 1) ${ }^{[16]}$. The values of EE x I are constants and are shown in Table 2.

$\mathrm{SPF}_{\text {Spectrophotometric }}=\mathrm{CF} \times \sum_{290}^{320} \mathrm{EE}(\lambda) \times \mathrm{I}(\lambda) \times \operatorname{Abs}(\lambda) \quad$ equation $-(1)$

Where EE: erythemal effect spectrum; I: solar intensity spectrum; Abs: absorbance of sunscreen product; CF: correction factor $(=10)$.

Table 2: Normalized product function used in the calculation of $\mathrm{SPF}^{[6,7,8,15]}$. Where EE: erythemal effect spectrum; I: Solar intensity spectrum

\begin{tabular}{|l|l|}
\hline$\square \mathbf{n m}$ & $\begin{array}{l}\text { EE * I } \\
\text { ( Normalized) }\end{array}$ \\
\hline 290 & 0.0150 \\
\hline 295 & 0.0817 \\
\hline 300 & 0.2874 \\
\hline 305 & 0.3278 \\
\hline 310 & 0.1864 \\
\hline 315 & 0.0837 \\
\hline 320 & 0.0180 \\
\hline Total & 1 \\
\hline
\end{tabular}

\section{Stability tests}

Stability tests were conducted to explore the effect of temperature and humidity on the storage ability of the emulsion ${ }^{[17]}$. This test was performed at $8 \pm 2^{\circ} \mathrm{C}, 25 \pm 2^{\circ} \mathrm{C}$ and $40 \pm 2^{\circ} \mathrm{C}$ where color, phase separation, $\mathrm{pH}$ change and liquefaction were observed at various time intervals during 28 days of incubation.

\section{Phase separation test}

The preparation stored at different temperatures, each $10 \mathrm{~g}$, was centrifuged directly after preparation at $5000 \mathrm{rpm}$ and $25^{\circ} \mathrm{C}$ for $10 \mathrm{~min}$ in a centrifuge tubes ${ }^{[18,19]}$. The test was repeated after $1^{\text {st }}, 7^{\text {th }}, 14^{\text {th }}, 21^{\text {st }}$ and $28^{\text {th }}$ days of storage.

pH determination 
The change in the $\mathrm{pH}$ of the preparation at different conditions was determined using a digital $\mathrm{pH}$ Meter ${ }^{[20,21]}$. The test was repeated at $1^{\text {st }}, 3^{\text {rd }}, 7^{\text {th }}, 14^{\text {th }}, 21^{\text {st }}$ and $28^{\text {th }}$ day of storage .

\section{Skin irritancy test}

The in vivo studies are conducted according to the protocol given by Institutional animal ethical comitte (IAEC) ${ }^{[22,23,24,25]}$. The Rats were divided into 5 groups. On the previous day of the experiment, the hair on the backside area of rats was removed. Animals in group 1 served as normal, without any treatment. Animals in Group 2 served as control were applied with marketed adhesive tape (official adhesive tape in USP). Prepared patches (blank i.e. without drug, and drug loaded) were applied onto nude skin of animals of $3^{\text {rd }}$ and $4^{\text {th }}$ groups. $0.8 \% \mathrm{v} / \mathrm{v}$ aqueous solution of formalin was applied as a standard irritant for animals in $5^{\text {th }}$ group. The animals were applied with new formalin solution each day up to 7 days and finally the application sites were graded according to a visual scoring scale, always by the same investigator.

\section{Microbial testing}

One gram of sample was dispensed in a $4 \mathrm{ml}$ sterile ringers solution containing $0.25 \%$ tween $80^{[26,27]}$. Six dilutions were made in the same dispersing vehicle and $0.1 \mathrm{ml}$ was plated on the appropriate solid medium using the surface viable method. Colonies were counted after the incubation. Aerobic counts were determined by inoculating 0.1 and $1 \mathrm{ml}$ of the homogenate sample onto triplicate sterile plates of prepared and dried Standard Method Agar. Plates were then incubated for $48 \mathrm{~h}$ at $35^{\circ} \mathrm{C}$. Plates containing $25-250$ colonies were counted and the average number of $\mathrm{CFU} / \mathrm{g}$ was calculated.

\section{Test for the presence of Pseudomonas aeruginosa and Staphylococus aureous}

Pseudomonas aeruginosa was enumerated on pseudomonas agar base (CM 559,Oxoid) supplemented with fucidin and cetrimide. Colonies were counted after two days of incubation at $25{ }^{\circ} \mathrm{C}{ }^{[27]}$. Population of St.aureus was determined by standard plating methods. Colonies of staphylococcus were selected, gram stained and observed for oxidase and catalase reactions to confirm their microbial presence. All the counts were transformed into logarithms of the number of colony forming units $(\log 10 \mathrm{CFU} / \mathrm{g})^{[28]}$.

\section{Yeast and mould counts}

The method involves enumeration of colonies on the sabouraud dextrose chloramphenicol agar medium ${ }^{[29]}$. Enumeration was carried out as a pour plate method . Microbiological tests were repeated for formulation at $25^{\circ} \mathrm{C}$ after $0,7,14,21$ and 28 days of preparation.

\section{Results}

The SPF of newly formulated emulsion is found to be 59.74 as shown in the table 3. The SPF of a formulation will be affected by various factors like use of different solvents in which sunscreen will be dissolved, the combination and the concentration of the ingredients, the nature of the emulsion, the effect and interactions of the diluents, the interaction of vehicle with the skin, addition of other active ingredients, the $\mathrm{pH}$ system and many factors that may increase or decrease the absorption of sunscreen ${ }^{[15]}$.

Table 3: In vitro SPF value form the cream formulation under different wave lenths of UV.

\begin{tabular}{|l|l|l|l|l|l|}
\hline s.no & $\begin{array}{l}\text { Wave length } \\
(\lambda \mathrm{nm})\end{array}$ & $\begin{array}{l}\text { EE x I } \\
\text { (normalized) }\end{array}$ & $\begin{array}{l}\text { Absorbance } \\
(\mathrm{A})\end{array}$ & $\begin{array}{l}\text { Ab x CF x } \\
\text { EE x I }\end{array}$ & $\begin{array}{l}\text { SPF }=\Sigma \mathrm{EE}(\lambda) \times \mathrm{I}(\lambda) \mathrm{x} \\
\text { Absorbance }(\mathrm{A}) \times 10\end{array}$ \\
\hline 1. & 290 & 0.0150 & 1.850 & 0.2775 & 59.74 \\
\hline 2. & 295 & 0.0817 & 1.861 & 1.520437 & \\
\hline 3. & 300 & 0.2874 & 5.100 & 14.6574 & \\
\hline 4. & 305 & 0.3278 & 5.151 & 16.884978 & \\
\hline 5. & 310 & 0.1864 & 9.235 & 17.21404 & \\
\hline 6. & 315 & 0.0839 & 9.235 & 7.748165 & \\
\hline 7. & 320 & 0.018 & 8.010 & 1.4418 & \\
\hline
\end{tabular}

Color, liquefaction and phase separation changes after four weeks were presented in the following table 4. The formulation was white in color during storage conditions at $8^{\circ} \mathrm{C}, 25^{\circ} \mathrm{C}$ and $40^{\circ} \mathrm{C} \pm 2^{\circ} \mathrm{C}$, up to 28 days of observation The viscosity of emulsion is often reported to play a vital role in its flow properties ${ }^{[5,6,]}$. As far as the findings of the present study, no liquefaction was observed for the emulsion in any of the storage conditions under investigation. The absence of liquefaction provided strong evidence for the stability of emulsion under investigation.

No phase separation was observed after centrifugation for the sample stored in conditions up to 21 days. This was presumably due to the proper homogenization speed during emulsion formulation which might have prevented the breakage of the formulations during testing. 
The $\mathrm{pH}$ of human skin normally ranges from 4.5 to 6 . Formulated cream had a pH value of 6.1 , which is close to the neutral $\mathrm{pH}$. The cream had stable $\mathrm{pH}$ values for almost all conditions tested. In the end of storage, at $40^{\circ} \mathrm{C}$, a statistically significant decrease in the $\mathrm{pH}$ of the cream was observed.

Table 4: Physical characteristics of formulated sample at experimental conditions. (-) indicates no changes was observed in the formulated sample

\begin{tabular}{|c|c|c|c|c|c|c|c|c|}
\hline \multirow[t]{2}{*}{ Properties } & \multicolumn{8}{|l|}{ Duration } \\
\hline & Temp ${ }^{\circ} \mathrm{C}$ & Ohrs & $24 \mathrm{hrs}$ & $3^{\text {rd }}$ day & $7^{\text {th }}$ day & $14^{\text {th }}$ day & $21^{\text {st }}$ day & $28^{\text {th }}$ day \\
\hline \multirow[t]{3}{*}{ Color } & 8 & - & - & - & - & - & - & - \\
\hline & 25 & - & - & - & - & - & - & - \\
\hline & 40 & - & - & - & - & - & - & - \\
\hline \multirow[t]{3}{*}{ Liqufication } & 8 & - & - & - & - & - & - & - \\
\hline & 25 & - & - & - & - & - & - & - \\
\hline & 40 & - & - & - & - & - & - & - \\
\hline \multirow[t]{3}{*}{ Phase separation } & 8 & - & - & - & - & - & - & - \\
\hline & 25 & - & - & - & - & - & - & - \\
\hline & 40 & - & - & - & - & - & - & - \\
\hline \multirow[t]{3}{*}{$\mathrm{pH}$} & 8 & 6.1 & 6.1 & 6.1 & 6.1 & 6.1 & 6.1 & 6.1 \\
\hline & 25 & 6.1 & 6.1 & 6.1 & 6.1 & 6.1 & 6.1 & 6.1 \\
\hline & 40 & 6.1 & 6.1 & 6.1 & 6.0 & 6.0 & 6.0 & 5.9 \\
\hline
\end{tabular}

Skin irritation studies on rat gave 0 scale for erythema as well as 0 level scale for edema as compared to the standard Formalin solution (table 3). The studies show that prepared cream is compatible with animal skin (Irritation barely perceptible) and can be used for further studies.

Figure 3: (a) Rat skin with standard irritant solution of formalin (Showing erythema); (b) Rat skin with test product (Showing no erythema); (c) Rat skin observing after 7days (healthy epidermis without any effects)

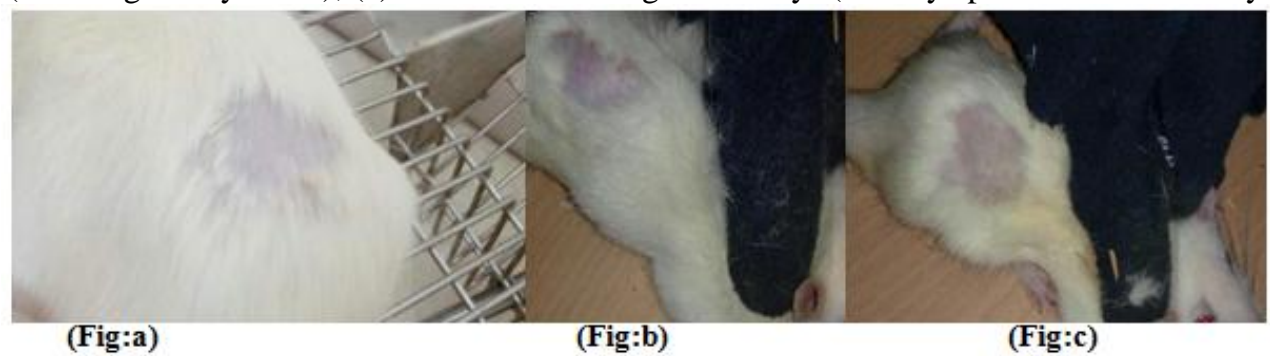

Table 3: Skin response in terms of scores are given where score 0 represents no erythema and edema formation; score 1 represents very slight erythema and edema.

\begin{tabular}{|l|l|l|l|l|}
\hline \multirow{2}{*}{ Skin Responses } & Time & Score & \multicolumn{3}{|l|}{} \\
\cline { 2 - 5 } & (Hrs) & Group 1 & Group 2 & Group 3 \\
\hline \multirow{3}{*}{ Erythema and Scar formation } & 1 & 0 & 1 & 0 \\
\cline { 2 - 5 } & 24 & 0 & 0 & 0 \\
\cline { 2 - 5 } & 48 & 0 & 0 & 0 \\
\hline Edema formation & 1 & 0 & 0 & 0 \\
\cline { 2 - 5 } & 24 & 0 & 0 & 0 \\
\cline { 2 - 5 } & 48 & 0 & 0 & 0 \\
\hline Primary irritation index (PII) & & $\begin{array}{l}\text { PII }=0 / 6 \\
(00)\end{array}$ & $\begin{array}{l}\text { PII }=1 / 6 \\
(0.17)\end{array}$ & $\begin{array}{l}\text { PII }=0 / 6 \\
(00)\end{array}$ \\
\hline
\end{tabular}

The $\log$ mean count recorded for the aerobic plate count of sample on day 0 was about $2.01 \log$ $10 \mathrm{CFU} / \mathrm{g}$. On day 28 of storage, the log mean count of aerobic plate count reached 3.33 for sample respectively as given in table 6, which did not approximate the maximum limit of $6.9 \log 10 \mathrm{CFU} / \mathrm{g}$ for aerobic plate count recommended ${ }^{[4,5]}$. There was no evidence for the presence of Pseudomonas and St.aures, thus confirming that the cream met the conventional standards. Yeast and molds have been tested in cosmetic products to asses microbiological safety and product quality during processing and storage.The levels of these microorganisms were noted to remain under the standard limit. In fact, the initial yeast and molds counts recorded for all treatments were under the detection limit. Moreover, the yeast and mould count values recorded for the formulated sample all the values obtained met the conventional standards specified with regard to fitness for human consumption. 
Table 6: Microbial load determined by aerobic plate count, P. aeruginosa, St. aureous and moulds detection during 28 days of storage at $25 \pm 2{ }^{\circ} \mathrm{C}$.

\begin{tabular}{|l|l|l|l|l|l|}
\hline & 0 time & 7 th day & $14^{\text {th }}$ day & $21^{\text {st }}$ day & $\mathbf{2 8}^{\text {th }}$ day \\
\hline Arobic plate count & $2.01 \pm 0.27$ & $2.11 \pm 0.19$ & $2.34 \pm 0.15$ & $2.96 \pm 0.15$ & $3.33 \pm 0.11$ \\
\hline P.aeruginosa & $<1$ & $<1$ & $<1$ & $<1$ & $<1$ \\
\hline St.aureus & $<1$ & $<1$ & $<1$ & $<1$ & $<1$ \\
\hline Yeast & $1.13 \pm 0.16^{\mathrm{a}}$ & $1.37 \pm 0.22^{\mathrm{a}}$ & $1.49 \pm 0.14^{\mathrm{a}}$ & $1.72 \pm 0.27^{\mathrm{a}}$ & $1.79 \pm 0.27^{\mathrm{a}}$ \\
\hline
\end{tabular}

$\pm \quad$ standard deviation of three replicates, $\mathrm{CFU}=$ colony forming units,

a $\quad=$ averages for different microbial analyses with different letters in the same Colum are different $(p<0.05)$.

\section{Discussion}

The emulsion is formulated using different oils like olive oil, almond oil, avocado oil, coconut oil and carrot seed oil. Carrot seed oil (natural SPF - 40) contains a-pinene, camphene, b-pinene, sabinene, myrcene, y-terpinene, limonene, b-bisabolene, geranyl acetate, and carotol. It helps in healing abscesses, boils and other skin disorders. It nourishes, tightens, and rejuvenates skin. It is mixed with carrier oils like almond oil, olive oil, and coconut oil for protection from its potential photosensitization and other effects of undiluted strength. Avocado oil (natural SPF - 15) contains high levels of healthy monounsaturated fats, phytosterols and antioxidants like vitamin-E. All of these nutrients help better in improving skin tone. As it penetrates into the dermis layer of our skin, it provides an extremely soft and hydrated facial skin. It is also recommended for treating acne, eczema and psoriasis ${ }^{[16,23,30]}$. Coconut oil (natural SPF -8 ) contains saturated fats which are useful in eliminating moisture loss through skin. It gives a healthy, smooth and even tone to the skin. It also contains capric, caprylic and lauric acids which have a very strong disinfectant and antimicrobial properties. Olive oil (natural SPF - 8) contains three major antioxidants namely vitamin E, polyphenols and phytosterols which help in protecting the skin from premature ageing. Hydroxytyrosol prevents free radical damage to the skin. It also enhances the exfoliation of dead skin cells. Almond oil (natural SPF - 5) is rich in vitamin- E, fats, protein and contains many essential nutrients. It makes skin healthier, reduces dark circles, delays signs of ageing, removes impurities and dead skin cells, reduces tan and treats psoriasis and eczema ${ }^{[31]}$. Lemon grass oil extracted from lemon grass is used to impart fragrance to the formulation has antimicrobial, antibacterial and anti-fungal properties. It is a natural astringent with some antiseptic properties.The formula also contains vitamin-E which helps in improving the texture of the skin and also in treating sun burns. Beeswax used in cream base preparation also helps in healing skin allergies and irritation ${ }^{[24,31]}$.

The present formulation shows 59.7 SPF that can show 98\% of UV B protection as shown in the table $7^{[32]}$. From the literature any sunprotective formulation with SPF greater than 50 must show protection even from UV A radiation ${ }^{[32]}$. From the UV absortion data it is clear that the present formulation can absorb $290 \mathrm{~nm}$ of UV A radiation.

Table 7 : SPF values and sunscreen UVB radiation absorption

\begin{tabular}{|l|l|}
\hline SPF & \%of Ultraviolet B radiation Blocked from the skin \\
\hline 2 & 50.0 \\
\hline 4 & 75.0 \\
\hline 8 & 87.5 \\
\hline 15 & 93.3 \\
\hline 30 & 96.7 \\
\hline 50 & 98.0 \\
\hline
\end{tabular}

\section{Conclusion}

The finding presented in the current study indicated that sunscreen cream containing all natural ingredients at different percentages ca be an effective sunprotective cream that can protect the skin from UV A as well as UV B radiation. Moreover all the tests such as microbiological assays, centrifugation, $\mathrm{pH}$ determination and stability tests met the conventional standards specified with regard to fitness for human use.

\section{Aknowledgements}

The authors are thankful to the management,Chalapathi Institute of Pharmaceutical Sciences for providing their support in completing this project.

\section{References}

[1] Elizangela Abreu Dutra, Daniella Almanca Gonclaves da Costa e Oliverira, Erika Rosa Maria Kedor Hackmann, Maria ines Rocha Miritello Santoro. Determination of sun protection of sunscreens by ultraviolet spectrophotometry. Brazilian Journal of Pharmaceutical Sciences. 2004; 40: 31. 
[2] Hamid A. K., Shafiyah S.,Shariq B., Jiyauddin K., M. Kaleemullah, Sameer A. D and S. Budiasih. Photoprotective activity ethanolic extracts and cream formulation of camellia sinensis and azadirachta indica. World Journal of Pharmaceutical Research 2015;.4(5): 422-435.

[3] L.Mbanga, M. Mulenga, P.T Mpiana, K. Bokolo, M. Munbwa, K. Mvingu. Determination of sun protection factor of some body creams and lotions marketed in Kinshasa by ultraviolet spectrophotometry. International journal of Advanced Research in Chemical Science 2014; 1(8):7-13.

[4] Slim Smaoui, Hajer Ben Hlima, Ines Ben Chobba, Adel Kadri. Development and stability studies of sunscreen cream formulations containing three photo-protective filters. Arabian Journal Of Chemistry, 2013;2:20.

[5] Somayeh Handali, Hyam Hosseini, Abdulghani Ameri, Eskandar Moghimipour. Formulation and evaluation of an antibacterial cream from Oxalis corniculata aqueous extract, Jundishapur. Journal of Microbiology 2011; 4(4): 255-260.

[6] Kotta Kranthi Kumar, K.Sasikanth, M.Sabareesh, N.Dorababu. Formulation and evaluation of Diacerein cream. Asian Journal of Pharmaceutical and Clinical research. 2011; 4(2):356-359.

[7] Sujith S Nair, Molly Mathew, Sreena K. Formulation and evaluation of herbal cream containing Curcuma longa. International Journal of Pharmaceutical and Chemical sciences 2012;1 (4):1362-1368.

[8] Mahapatra Annada Prasad, Mishra Dipak Kumar, Panda Prabhudutta. Formulation and evaluation of cream prepared from Croton Sparsiflorus Morong and their wound healingactivity. International Journal of research and publication 2012; 3(6):803-807.

[9] Kerr AC, Niklasson B,Dswe RS, Escoffier AM, Karasteva M, Sanderason B, Ferguson J . A double-blind, randomized assessment of the irritant potential of sunscreen chemical dilutions used in photopatch testing.Contact Dermatitis 2009;60(4):203-9.

[10] Chatelain E, Gabard B, Surber C. Skin penetration and sun protection factor of five UV filters: effect of the vehicle. Skin Pharmacol Appl Skin Phys 2003; 16:28-35.

[11] Premkumar, T.Muthukumaran, V.Ganesan, Shanmugam R, Priyanka D.L. Formulation and evaluation of cream containing antifungal agents, antibacterial agents and corticosteroids. Hygeia. Journal for drugs and medicines 2015; 6(2):5-16.

[12] Sandhu Premjeet, Bilandi Ajay, Kumar Sunil, Kapoor Bhawana, Kataria Sahil, Rathore Divashish Bharadwaj Sudeep. Additives in topical dosage forms. International Journal of Pharmaceutical, Chemical and Biological sciences 2012; 12 (1): 78-96.

[13] Akhtar N, Khan MS, Mahmood T, Khan HMS, Iqbal M, Bashir S. Formulation Development and moisturizing effects of a topical cream of Aloe vera extract. International Science index 2011;5(3):128-136.

[14] Muhammad K. Waqas, Naveed Akhtar, Mahmood Ahmad, Ghulam Murtaza, Haji M.S. Khan, Muhammad Iqbal, Akhtar Rasul, Naveed S. Bhatti. Formulation and characterization of a cream containing extract of Fenugreek seeds. Acta Poloniae Drug research 2010; 67(2):173-178.

[15] Ravishankara M.N, Shrivastava, Neeta, Padh, M.Rajani. Antioxidant activity measured of methanolic extract of Hemidesmusindicus root bark in several invitro and invivo models. International Journal Of phytotherapy and Phytopharmacology 2002;9:153-60.

[16] Kamkaen N, Phuntuwate w, Samee W, Boonrod A, Treesak C. The investigation of the rabbit and human skin irritation of herbal anti-wrinkle cream. Thai pharm health Sci Journal 2007; 2(1):20-5.

[17] Herbert, A.L.Martin, M.R.Gilbert. Pharmaceutical emulsions pharmaceutical dosage forms: Disperse systems. 1988; Vol.1, Marcel Dekkar,New York and Basel .199-240, 285-288.

[18] Matousek J.L, K.L.Campbell, I.Kakoma, P.F.Solter. Evaluation of the effect of pH on invitro growth of Malasseziapachydermatis. Can J Vet Res.2003; 67:56-59.

[19] C.Malsamutlaungi, Nath D.K, Jamatia I, Lianhimgthangi, Zarzoalina E, PachuauL. Determination of sun protection factor (SPF) number of some aqueous herbal extracts. Journal of Applied Pharmaceutical sciences 2013;3(9): 150-151.

[20] Kale S, Bhandre S,Gaikwad M, Urunkar V, Rajmane A.. Formulation and invitro evaluation for sun protection factor of Lutein ester extracted from Tagetesecreta Linn flower sunscreen creams. RJPBCS 2011;2(3): 947-955.

[21] A.K. Mishra, A. Mishra, P. Chattopadhyay. Evaluation of Sun Protection factor of some marketed formulations of sunscreens by Ultraviolet spectroscopic Method. Journal of Current pharma research 2001; 5(1):32-35.

[22] Vijayaraghavan Sudhahar, Vadivelu Balasubramanian. Sun protection factor determination of marketed sunscreen formulation by in vitro method using UV-VIS spectrophotometer. Archives of Applied Science Research 2013;5(6): 119-122.

[23] Priyanka Kantivan Goswami, Mayuri Samant, Rashmi Srivastava. Natural Sunscreen agents: A review. Scholars Academic Journal of pharmacy 2013; 2(6): 458-463.

[24] Kareru, P.G, Keriko, J.M, Kenji, G.M, Thiong .O, G.T, Gachanja, A.N, Mukiira, H.N. Antimicrobial activities of skincare preparations from plant extracts. Afican Journal traditional 2010; 7(3):214-218.

[25] Bakos.L, M.Wagner, Leite, C.L.Sperhacke, dzekaniak, K.S.Gleisner. Sunburn, sunscreens and phenotypes. International Journal of Dermatology 2002; 41:562-557.

[26] V.Sudhakar, Balasubramanian V. Sun Protection factor determination of marketed sunscreen formulation by invivo method using UV-VIS spectrophotometer. Archive of Applied sciences and Research 2013;5(6): 119-122.

[27] Kamlesh J. Wadher, C.L.Lakhotia, M.J. Umekar Formulation and evaluation of cream of Azadirachtaindica leaves extracts on skin renewal rate. International Journal of Chem Tech Research 2009; 1: 88-95.

[28] M.Shekhar, S.Shetty, G.Lekha, Mohan K. Evaluation of invitro antioxidant property and radio protective effect of the constituent medicinal plants of a herbal sunscreen formulations. International Journal Of Pharmaceutical Frontier research 2012;2(2):90-96.

[29] Katiyar, S.K and Elmets C. A.Green tea antioxidants and skin protection. International Journal Of Oncology 2001;18: 1307-1313.

[30] Wilson R. The basic principle of aromatherapy, In aromatherapy: Essential oils for Vibrant health and beauty, Part one. Pengine Group, New York, 2002:40.

[31] Kulmer WD, Daniels TC. Sunscreen compounds. Journal of the American Pharmaceutical Association 1948; 37(11):474-476.

[32] DutraE.A,Oliveira D.A.G.C., Kedor-Hackmann E.R.M.,Santoro M.I.R.M. Determination of Sun Protection Factor (SPF) of sunscreens by ultraviolet spectrophotometry. Bra.J.Pharm.Sci.2004;40:31. 